\title{
Sellafield under scrutiny
}

\section{London}

THE UK Health and Safety Executive (HSE) plans to extend the survey which earlier this year suggested a link between the high incidence of leukaemia in children in the West Cumbrian village of Seascale and their fathers' exposure to radiation at the Sellafield (formerly Windscale) nuclear reprocessing plant (see Nature 343, $679 ; 1990$ ).

The new HSE study, which will cover everybody who has worked at Sellafield since 1949 , is one of a number of projects designed to investigate the controversial link between paternal radiation exposure and childhood cancer originally suggested by Professor Martin Gardner of the University of Southampton. These studies should soon begin, once official clearances have been obtained and problems with data confidentiality resolved.

The HSE study will compare the full work histories of the fathers of leukaemic and unaffected children, looking at other factors besides radiation dosages alone. Exposure to carcinogenic chemicals, for example, has been put forward as an alternative explanation for Gardner's results. Any Sellafield workers wishing to have their records excluded from the study must get in touch with the HSE by the end of November.

Gerald Draper, from the University of Oxford, plans a wider study, linking Oxford's National Registry of Childhood Tumours with the National Radiological Protection Board (NRPB)'s radiation dose records for all British radiation workers. But Draper says progress has been "snarled up" because of the confidentiality of vital data held by the Office of Population Censuses and Surveys (OPCS).

To link the two databases, Draper needs to know the date of birth of the fathers of leukaemic children, to check that matches between the names of fathers and workers on the NRPB database are genuine. A 1938 act of parliament allows only OPCS staff access to these data.

Draper says a compromise should be possible, with OPCS staff doing some preliminary analysis and providing the Oxford team with summary data, so that individuals cannot be identified. He now hopes to get approval for the study within the next few months.

If the 'Gardner effect' is real, and the risk factor is anything like as large as Gardner suggested (a seven to eightfold increase in the chance of fathering a leukaemic child for fathers receiving a total radiation dose of 100 milliSieverts, or more than $10 \mathrm{mSv}$ in the six months before conception), Draper says his survey should be large enough to detect the effect.

In Scotland, where population records

are subject to a different law, data confidentiality has not been a big problem. But studies have still been held up by the need to get official approval from the HSE and the Department of Health.

The Committee on Medical Aspects of Radiation in the Environment, independent scientific advisers to the UK government, said that further study following the

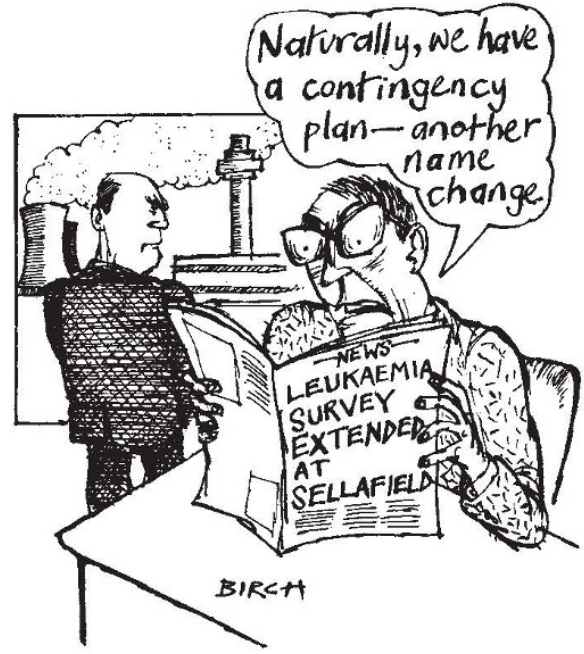

Gardner report should be co-ordinated centrally to avoid unnecessary intrusion into the lives of British radiation workers (see Nature 344, 576; 1990). This was inRESEARCH IN JAPAN

\section{Rent-a-lab welcome for foreigners}

\section{Tokyo}

JAPAN's Ministry of International Trade and Industry (MITI) is opening up some of its major research programmes to foreign participation and making some of its bestequipped facilities available for rent in a campaign designed to counter foreign complaints that the Japanese research system is closed to outsiders.

At the end of last month, MITI announced that three huge programmes run by the New Energy and Industrial Technology Development Organization (NEDO) are now open to foreign participation. The programmes are in advanced chemical processing technology, software development and in the design of clothes that "reflect human sensibility". But the change in policy is unikely to bring in a horde of foreign companies as it was announced only in the MITI Gazette and scarcely a month remains for applications to be filed.

More foreign interest may be generated from a second MITI decision, announced last week, to open some facilities for public use. For as little as $¥ \mathbf{2 0 0 , 0 0 0}(\mathbf{\$ 1 , 4 6 0 )}$ foreign companies or individuals will be able to rent a ten-second free-fall ride aboard a tended to avoid duplication of intrusive studies requiring questionnaire data, but has also held back those simply involving the analysis of existing records.

Leo Kinlen, from the Cancer Research Campaign's laboratories in Edinburgh, last week received approval for a study that will link records of Scottish leukaemia cases and controls with radiation records for the entire Scottish nuclear industry. $\mathrm{He}$ hopes to complete arrangements for access to the industry's radiation dose records within the next few weeks. A second study is planned by the Scottish Health Service, but both Scottish surveys may be too small to give a definitive answer on the existence of the Gardner effect. Nevertheless, Kinlen says the studies should give an indication of the "size of the problem [in Scotland], if problem there is".

Two surveys commissioned to investigate the smaller excesses in leukaemia incidence near nuclear sites at Dounreay in Scotland, and Aldermaston and Burghfield in southern England, are now nearing completion. The Dounreay study should be published within the next few months, the Aldermarston and Burghfield study before the end of 1991 .

Peter Aldhous

- Researchers from AEA Technology show that plutonium-239 does not accumulate in large quantities in human testes. This has been put forward as a mechanism to explain the Gardner effect. See Scientific Correspondence page 521. microgravity capsule that can be shot down a disused coal mine shaft in Hokkaido. The mine shaft at the Japan Microgravity Center is 710 metres deep and MITI claims that it provides longer near-zero-gravity conditions than at any other ground-based facility.

Also available for rent will be some of the world's most powerful ion beams, courtesy of the new Ion Engineering Center in Kansai science city, and the facilities of the Research Center for Industrial Utilization of Marine Organisms, the Japan Ultrahigh-Temperature Material Research Center and the Applied Laser Engineering Center.

All these institutes are run as corporations by NEDO which was reorganized in 1988 to absorb most of MITI's major research and development projects. The corporations receive half of their funding in the form of investment from NEDO, private companies and local government. Rental charges are intended to cover operating costs and not to provide a profit, says MITI. At first, the major users are expected to be the Japanese companies that have already invested in the institutes.
David Swinbanks 